\title{
The model of system predicting with the use of dynamic arrangement schemes ${ }^{\mathrm{a}}$
}

\author{
Oksana Pirogova ${ }^{1}$, Vladimir Plotnikov ${ }^{2 *}$, and Andrey Prolubnikov ${ }^{3}$ \\ ${ }^{1}$ Peter the Great St. Petersburg Polytechnic University, Institute of Industrial Management, \\ Economics and Trade, Higher School of Service and Trade, 195251 Politekhnicheskaya st. 29, \\ Russian Federation \\ ${ }^{2}$ The Saint Petersburg State University of Economics, Faculty of General Economics and History of \\ Economic Thinking, 19102321 Sadovaya st. 21, Russian Federation \\ ${ }^{3}$ Dushanbe Subdivision of National University of Science and Technology "MISIS", Nazarshoyeva \\ st. 7, Tajikistan
}

\begin{abstract}
The basic problems are considered in the paper connected with solving the problems of forecasting development of enterprises in the conditions of growth of volumes and intensity of information flows in consequence of digitalization of economic processes. The aspects of using a cost approach and also life cycle models of enterprises in the tasks of building the system of planning and predicting activity are considered. An approach to forecasting development of an enterprise on the basis of a dynamic model of the cost growth is proposed by the authors. As the main general indicator fundamental cost of an enterprise is considered, which includes four basic elements. A principle which takes into account dynamic cosubordination of basic indicators of growth of the fundamental enterprise cost is accepted as a basis for the predicting model. A variant of a structure of an adaptive model of dynamic cosubordination of basic indicators is suggested; the structure changes depending on the stage of the life cycle. The represented approach enables taking into account contradictory requirements to the choice of key indicators of development, changing at different stages of the life cycle, and also estimating and predicting the activity of an enterprise from unified positions.
\end{abstract}

\section{Introduction}

The millennium of transformation to digital economy reveals new opportunities in the sphere of managing business [1]. By means of increasing flexibility in processing significant volumes of information arrays and expanding opportunities for accessing the information enterprise management gets new resources for generating new knowledge in

\footnotetext{
${ }^{\mathrm{a}}$ This paper is an output of the science project of the government task of Ministry of education and science of the Russian Federation \# 26.3546.2017/PCH "Development fundamentals of analysis and prediction of structural and dynamic parameters of the regional economy are based on the integration of the Russian and world experience of management of territorial development and modern scientific doctrines"

*Corresponding author: plotnikov_2000@mail.ru
} 
real time scale [2]. This knowledge, in its turn, facilitates growth of management efficiency and, consequently, competitive ability of enterprises. New knowledge and new models of its extracting and using enable shortening the time for analysis and taking decisions enable considering a greater number of factors and modeling future problems and challenges which deal with effective development of enterprises.

Thanks to digital economy even a very small enterprise becomes the owner of a huge volume of information about its activity, on condition that its system of business and management accounting is correctly organized. The growth of information volumes about the enterprise activity in different aspects increases awareness of managers and owners of the enterprise activity state. On the other hand, development of digital economy gives new opportunities for accessing and using external information which is also important for making management decisions. This information becomes more extensive, cheaper and the promptness of its obtaining constantly grows. At that, as the technology of distributed data storage develops, possibilities for using actual information in enterprise management become more and more accessible [3].

Consequently, the value of the models increases: the models make building the process of enterprise development possible with the use of the entire array of aposteriori information on the activity of the enterprise, also using external information which preconditions the activity of the enterprise and data on macroeconomic and regional forecasts [4]. In addition to that, formulation of such models is connected with certain hardships which are preconditioned, first of all, by a great number of correlation relationships between indicators which reflect the activity of the enterprise. A very important factor is the possibility for accounting changes of goal sets in such models and also taking into account behavior of enterprises at different stages of their life cycle.

\section{The problems of predicting the development of an enterprise at the current stage}

Planning and, especially, predicting the activity and development of an enterprise are the most complex elements in the activity control circuit of the enterprise and they are connected with strategic planning which is aimed at providing the enterprise managers and owners with information on possible alternative directions for its development depending on the condition of the internal and external environment. Predicting is one of the main procedures of strategic planning; it's about composing alternative long-term and mediumterm forecasts of the activity of the enterprise and estimating the degree of executability of the given forecasts $[5,6]$.

Currently, the methods of simulation and economic-statistical modeling are most widely spread $[7,8]$. They are based on the use of statistical regularities as one of the forms of expressing the variety of economically stable connections between separate elements of an enterprise as a system and also between enterprises in the external environment which is constantly changing. That is to say, digital economy enables using the advantages of external and internal information awareness of the enterprise management to the full extent.

Currently, methods of predicting the activity of an enterprise based on the complex of economic and financial indicators are worked out in detail. At the same time, the approach to predicting the development of an enterprise may be built on the basis of the cost approach $[9,10]$. Without going into all the peculiarities of this approach, we will mark its most important aspects, namely:

- fixation of the activity on the growth (gain) of cost and not on its concrete value;

- commitment to providing stable long-term active existence of the enterprise (that is, the life time of the enterprise is not limited and not considered as a project limited in time); 
- commitment to the future of the enterprise and that implicates finding answers to the question: "What is it necessary to do today in order to provide the required rates of growth of the cost in future?"

- fixation not only on the managers' and owners' interests but also on the interests of other groups of people interested in the activity of the enterprise (stakeholders);

- an objectively proved possibility of influencing the cost of an enterprise through managing its operational, financial and investment activities.

The suggested theoretical projects, as a rule, don't take into account the stage of the life cycle of an enterprise. At the same time, competent accounting of this factor at each stage enables concentrating on the most important, from the point of view of cost ideology, indicators and, in doing so, ensure stable and sequential development of the enterprise [11].

While predicting the development of the enterprise it is important to define basic models which are in the basis of its activity at each stage of its life cycle, to determine the horizon and the goals of predictive modeling. This approach allows the enterprise to select the most effective development pathway at each stage of its life cycle, ensuring in doing so progressive stable development.

\section{Integration of life cycle models with the conception of the cost approach for managing the enterprise}

The main task of life cycle models is distinguishing periods in the development of an enterprise; each one of them is characterized by certain stable features. At this, control models should directly consider these features and they should be built on the basis of a detailed report.

Historically, the appearing and development of life cycle models was connected with the analysis of organizational problems in the enterprise activity which is associated with distributing rights, privileges and responsibility [12]. However, further it became clear that expansion of life cycle models to aspects of financial, operational and investment activity of an enterprise may also bring significant positive effects. This idea was mostly widely used for managing enterprise finances [13]. Thus, it is suggested to consider cost models (of the $E V A, M V A$ types) only at the stage of maturity in the work [14], and in our opinion that is not enough. It is also suggested to use cost models at different stages of the life cycle in the work [15], however, there are no specific recommendations in this work.

A deep economic analysis of cost and its dynamics through the prism of the life cycle stages of an enterprise is carried out in the works $[8,16]$ and it is shown that the cost growth indicator of an enterprise defined through money flows is dependent on the complex internal structure of the cost generation system and is formed thanks to money flows from operational, investment and financial activity of an enterprise. Dynamics of these components of the money flow and integral value of the net cash flow of an enterprise at life cycle stages is represented in Table 1. 
Table 1. Dynamics of rates of growth, components of net cash flow of an enterprise.

\begin{tabular}{|c|c|c|}
\hline Life cycle stage & Main task & $\begin{array}{l}\text { Basic profile of a dynamically } \\
\text { harmonized system }\end{array}$ \\
\hline Founding stage & $\begin{array}{l}\text { To prove viability and consistency } \\
\text { of a business-project }\end{array}$ & $\begin{array}{l}T\left(C F_{\mathrm{O}}\right)>T\left(C F_{\mathrm{F}}\right)>1>T\left(C F_{\mathrm{I}}\right) \\
T\left(C F_{\Sigma}\right)<0\end{array}$ \\
\hline $\begin{array}{l}\text { Growth } \\
\text { stage (youth) }\end{array}$ & $\begin{array}{l}\text { Transformation of the money flow } \\
\text { into the formed market share }\end{array}$ & $\begin{array}{l}T\left(C F_{\mathrm{O}}\right)>T\left(C F_{\mathrm{F}}\right)>T\left(C F_{\mathrm{I}}\right)>1 \\
T\left(C F_{\Sigma}\right)>>1\end{array}$ \\
\hline \multirow{2}{*}{$\begin{array}{l}\text { The stage of } \\
\text { stability (maturity) }\end{array}$} & \multirow{2}{*}{$\begin{array}{l}\text { Building up an effective } \\
\text { competitive business-model }\end{array}$} & $\begin{array}{l}T\left(C F_{\mathrm{O}}\right)>T\left(C F_{\mathrm{I}}\right)>T\left(C F_{\mathrm{F}}\right)>1 \\
T\left(C F_{\Sigma}\right)>1\end{array}$ \\
\hline & & $T\left(C F_{\mathrm{I}}\right)>T\left(C F_{\mathrm{F}}\right)>T\left(C F_{\mathrm{O}}\right)>1$ \\
\hline \multirow[b]{2}{*}{ The stage of decline } & \multirow{2}{*}{$\begin{array}{l}\text { Preparing to effective } \\
\text { transformation of an enterprise in } \\
\text { accordance with the requirements of } \\
\text { competitive conditions }\end{array}$} & $T\left(C F_{\Sigma}\right)<>1$ \\
\hline & & $\begin{array}{l}T\left(C F_{\mathrm{O}}\right)>1>T\left(C F_{\mathrm{F}}\right)>T\left(C F_{\mathrm{I}}\right) \\
T\left(C F_{\Sigma}\right)<0\end{array}$ \\
\hline
\end{tabular}

The following designations are used in this table: $T\left(C F_{\mathrm{O}}\right)$ - the rate of growth of the money flow from operational activity, $T\left(C F_{\mathrm{F}}\right)$ - the rate of growth of the money flow from financial activity, $T\left(C F_{\mathrm{I}}\right)$ - the rate of growth of the money flow from investment activity, $T\left(C F_{\Sigma}\right)$ - the rate of growth of integral value of the net cash flow of the enterprise.

The authors introduced a transition line in Table 1 between the stages of stability and decline (marked by color filling in the table). This addition has not technical but conceptual character. This transition situation corresponds to the point of bifurcation - the situation in which an enterprise may be. Development after its passing may follow two scenarios: optimistic (maintaining competitive ability and stable functioning, preserving and increasing value of an enterprise) or pessimistic (losing competitive advantages, reduction in value of an enterprise).

At this, the first scenario, in case of taking decisions of an innovative type by the management of the enterprise, may lead to transition to the next cycle of its life. In this case the enterprise, owing to the implemented technological, organizational, market and other innovations, passes to a new stage of growth and stability, that is, a new phase of development is implemented which presupposes repeating the stages of youth and maturity. Such a transition to a new stage of development is possible only in the event when benefit from investments into expanded production on the innovative basis starts to bring income which is comparable to the main activity of the enterprise.

The main idea of the considered approach reflected in the form of Table 1 is that at different life cycle stages of an enterprise dynamics of components of its value differs and, definitely, it is necessary to take it into account when building up a system of enterprise management on the basis of its value. Nonhomogeneity of the value indicator as an economical category is considered and justified in detail in the works $[17,18]$.

To estimate each component of the cost value a chain of private indicators may be used which characterizes the value and quality of this or that component of the cost. Moreover, in a general case these indicators may be combined in a system on the basis of principles of dynamic concurrence. This approach was earlier developed by the authors and represented in the article [16]. The chain of dynamic concurrence of separate elements of the fundamental cost [8] is the basic one according to the approach suggested by us:

$$
I\left(V_{\mathrm{DF}}\right)>I\left(V_{\mathrm{I}}\right)>I\left(V_{\mathrm{O}}\right)>I\left(V_{\mathrm{B}}\right)>0,
$$

where $I\left(V_{\mathrm{B}}\right), I\left(V_{\mathrm{O}}\right), I\left(V_{\mathrm{I}}\right), I\left(V_{\mathrm{DF}}\right)$ are rates of gain of balance, operational, investment components and the component of dynamic flexibility (potential) of the fundamental cost of a trade enterprise, respectively. The cost component of dynamic flexibility is the cost of direct and indirect abilities of an enterprise to adapt to changes of external environment and also to transform it for its own benefit. 
The represented model is true only at the stage of maturity, at the same time; the task of achieving the cost growth at other stages of the life cycle requires applying other kinds (schemes) of dynamic arrangement. The schemes of dynamic arrangement of private factors suggested by us are represented in Table 2. It should be noted that the moment of transition from the stability (maturity) stage to decline stage is specially emphasized in this table like in the previous one.

But, unlike Table 1, where the growth rates of the components of the company's cash flow are considered, the rate of increase in the value of the enterprise is considered here. A very important contribution into the cost growth at the maturity stage and passing over to a new development cycle is made by the component of dynamic flexibility value (VDF) which is an estimation of competitive advantages, intellectual capital and also other direct and indirect abilities of the enterprise to change its internal environment in the context of external environment changes. If this cost component is developed insufficiently it won't allow the enterprise to implement the required internal transformations and it will lead it to the stage of decline.

Table 2. Schemes of dynamic arrangement of gain rates of the basic factors of the enterprise value growth system.

\begin{tabular}{|l|l|}
\hline Life cycle stage & Basic profile of a dynamically harmonized system \\
\hline Founding stage & $I\left(V_{\mathrm{O}}\right)>0$ \\
\hline The stage of growth (youth) & $I\left(V_{\mathrm{O}}\right)>I\left(V_{\mathrm{I}}\right)>I\left(V_{\mathrm{B}}\right)>0$ \\
\hline \multirow{2}{*}{ The stage of stability (maturity) } & $I\left(V_{\mathrm{O}}\right)>I\left(V_{\mathrm{I}}\right)>I\left(V_{\mathrm{D}}\right)>I\left(V_{\mathrm{DF}}\right)>0$ \\
\cline { 2 - 2 } & $I\left(V_{\mathrm{DF}}\right)>I\left(V_{\mathrm{I}}\right)>I\left(V_{\mathrm{O}}\right)>I\left(V_{\mathrm{B}}\right)>0$ \\
\cline { 2 - 2 } The stage of decline & $I\left(V_{\mathrm{B}}\right)>0$ \\
\hline
\end{tabular}

\section{Predicting development of an enterprise with the use of schemes of dynamic arrangement}

The variant of the adaptive variant of dynamic arrangement of growth rates for basic factors of an enterprise value growth suggested above can be used for building up a scheme of predicting development of the enterprise.

In order to account for correlation between the main factors of value growth through basic factors - growth rates, the method of system predicting can be used, suggested in the work [11]. The theory of potentials is at the core of analytical methods of system analysis. According to this theory any object or system represents a multidimensional dynamic object or a system because it is described with multiple factors. A notion of "shalanovskiy process" is suggested for predicting; it is a non steady accidental process the state of which at a moment of time depends on the state at the previous stage. The basic element of the approach is the Shalanov's chain which is built on the basis of recurrent relation:

$$
X(t+1)=B\left(t-1, t, \sigma_{j}\right) X(t),
$$

where $X(t)$ is the state of the system at the moment of time $t$.

$X(t+1)$ - the state of the system at the moment of time $t+1$.

$B\left(t-1, t, \sigma_{j}\right)$ - transfer matrix based on accounting for retrospective data;

$\sigma_{j}$-mean-square deviation of attributes which characterize the system development level.

Predicting the system state is implemented on the basis of Shalanov's chains on the basis of the following algorithm:

$$
X(t+1)=B\left(t-1, t, \sigma_{j}(1, t)\right) X(t)
$$




$$
\begin{gathered}
X(t+2)=B\left(t, t+1, \sigma_{j}(1, t+1)\right) X(t+1) ; \\
X(t+\mathrm{n})=B\left(t+n-2, t+n-1, \sigma_{j}(1, t+n-1)\right) X(t+n-1) .
\end{gathered}
$$

Calculating the transfer matrix at each stage is implemented on the basis of using the potential theory. While using the given method it is suggested to work not with the factor values influencing the cost but with the rates of their changing. In this case the model of prediction includes growth rates of separate factors of activity.

A system of factors for forming a dynamic model of development of a trade enterprise on the basis of the cost growth by using the system of factors for estimating different components of the cost value is suggested in the work [8,9]; the system reveals all the main components of each type of the fundamental cost of the enterprise. The scheme of the noted dynamic model at the maturity stage can be expressed in the following way:

$$
\begin{gathered}
I\left(V_{\mathrm{B}}\right)=I(N A)>I(I C)>0 ; \\
I\left(V_{\mathrm{O}}\right)=I(N P)>I(O I)>I(G I)>I(R)>0 ; \\
I\left(V_{\mathrm{I}}\right)=I(R I)>I(N P V)>I(I)>0 ; \\
I\left(V_{\mathrm{DF}}\right)=I(I n C)>0 .
\end{gathered}
$$

In the system of equations and inequations (4): $I(N A)$ - net assets gain rate; $I(I C)$ - gain rate of the invested capital, $I(N P)$ - gain rate of the net profit; $I(O I)$ - gain rate of the sales profit; $I(G I)$ - gain rate of the gross income; $I(R)$ - gain rate of sale proceeds; $I(R I)$ - gain rates of investment profitability; $I(N P V)$ - gain rate of the net present value, $I(I)$ investments gain rate; $I(\operatorname{In} C)$ - gain rate of the innovation capital. On the basis of dynamic models represented in Table 2 and the equations (4) an algorithm of predicting the enterprise cost value can be made which includes the following sequence of actions.

The calculation of the current cost value of an enterprise $V$ on the basis of $M V A$ or $C V A$ methods.

Calculation of historical values of basic factors determining the cost of the enterprise: $N A, I C, R, G I, O I, N P, I, N P V, R I, I n C$, and also their gain rates.

Estimating the stage of the enterprise development and selecting the model of the cost growth in accordance with Table 1.

Calculating the transfer matrix at the predicting stage:

$B\left(t+n-2, t+n-1, \sigma_{j}(1, t+n-1)\right)$ based on accounting for the retrospective data (here $\mathrm{n}$ is an iteration step)

Calculating the predicted values of gain rates of basic factors determining the cost of the enterprise at the stage of predicting $(t+n)$ :

$X(t+n)=B\left(t+n-2, t+n-1, \sigma_{j}(1, t+n-1)\right) X(t+n-1)$.

Calculating the predicted values of gain rates of the fundamental cost of the enterprise at the stage of predicting $(t+n)$, using the components - balance, operational, investment and the component of dynamic flexibility respectively:

$\Delta V_{\mathrm{f}(t+n)}=\Delta V_{\mathrm{B}(t+n)}+\Delta V_{\mathrm{O}(t+n)}+\Delta V_{\mathrm{I}(t+n)}+\Delta V_{\mathrm{DF}(t+n)}$

Calculating the predicted value of the fundamental cost of the enterprise:

$V_{\mathrm{f}(t+n)}=V_{\mathrm{f}(t+n-1)}+\Delta V_{\mathrm{f} t+n)}$.

Stages connected with calculating the matrix of transition may be repeated the required number of times depending on the size of the predicting period.

Unlike algorithms of predicting considered within the framework of development of Shalanov school methods where dimensional values of enterprise activity factors are used, this approach deals with predicting gain rates of the main factors of the enterprise financial economic activity, as relative factors which first of all characterize the quality of the system.

It allows to avoid the influence of trend changes in the original data and from the other side it enables preserving the main advantage of the given method of predicting - 
systematic approach as complex accounting for all basic factors influencing the results of functioning of the system being modeled.

\section{Conclusions}

A modification of the method of predicting the cost of an enterprise on the basis of Shalanov's chains is suggested; this modification enables implementing the concept of system predicting. The represented method differs from the known methods in using principles of system dynamics when growth of private cost parameters is considered together with other factors of financial and economic activity of an enterprise. The structure of fundamental cost of an enterprise is taken into account in the suggested approach, and also principles of dynamic compatibility of the parameters used for evaluating the quality of the enterprise development on the basis of its cost are observed.

The second important distinguishing feature of the suggested approach is flexibility in selecting the basic model of cost growth which enables adequate accounting of changes in the enterprise goals at each stage and adjusting differences between the change in basic factors of productivity and efficiency of its activity at each stage of development on the one hand and fixation on cost growth as integral factor of development efficiency of an enterprise on the other hand.

\section{References}

1. E. J. Malecki, B. Moriset, The digital economy: Business organization, production processes and regional developments (Routledge, London, 2007)

2. D. Helbing, Thinking ahead-essays on big data, digital revolution, and participatory market society (Springer International Publishing, Cham, 2015)

3. S. Graham, D. Wood, Critical Social Policy, 23 (2) (2003)

4. Y. Vertakova, O. Grechenyuk, A. Grechenyuk, S. Emelianov, Proceedings of the 29th International Business Information Management Association Conference - Education Excellence and Innovation Management through Vision 2020: From Regional Development Sustainability to Global Economic Growth (2017)

5. N. V. Shalanov, Economic Diagnostics of Efficiency of a Trade Enterprise Activity (Publishing House "Omsk Economics Institute", Omsk, 2008)

6. E. V. Sokolov, A. Y. Kiselev, Controlling, 3 (27) (2008)

7. Z. K. Likhanova, Economic Analysis: Theory and Practice, 2 (2009)

8. O. E. Pirogova, V. A. Plotnikov, News of the Saint Petersburg University of Economics, 2 (104) (2017)

9. O. E. Pirogova, V. A. Plotnikov, News of the Saint Petersburg University of Economics, 4 (106) (2017)

10. V. V. Belov, V. I. Chistyakova, Business-informatics, 4 (06) (2008)

11. N. V. Shalanov, Economic Aspects (NGTU, Novosibirsk, 2008)

12. I. Adizes, Corporate Lifecycles: how and why corporations grow and die and what to do about it (Prentice Hall, New Jersey, 1988)

13. Y. Vertakova, V. Plotnikov, Economic Annals-XXI, 156 (1-2) (2016)

14. J. Stern, G. Stewart, D. Chew, Journal of Applied Corporate Finance, 8 (2) (1995)

15. L.E. Greiner, Harvard Business Review, 50 (4) (1972)

16. O. Pirogova, V. Plotnikov, Proceedings of 17 th International Scientific Conference Proceedings (Part IV) (2017) 
17. J. D. Martin, J. W. Petty, Value Based Management - The corporate response to the shareholder revolution (Harvard Business School Press, Harvard, 2000)

18. G.B. Stewart, The Quest for Value: A Guide for Senior Managers Harper Business (HarperCollins Publishers, New York, 1991) 